\title{
O corretor automático substitui o Revisor Profissional?
}

\author{
Stella Almeida Moreira - FALE/UFMG
}

RESUMO: O corretor automático é um bom instrumento para a revisão de texto, mas está longe de substituir o revisor profissional, pois ao corrigir erros gramaticais e ortográficos nem sempre o faz corretamente. Tampouco corrige problemas como: clareza de idéias, sintaxe, coesão, coerência textual e semântica, uma vez que essas questões irão depender da competência do revisor.

O corretor eletrônico é um bom instrumento para a revisão de texto, mas ainda está longe de substituir o revisor profissional humano. O software é apenas um auxiliar da revisão, pois serve para corrigir erros de digitação e/ou gramaticais e, mesmo assim, nem sempre o faz corretamente. Tampouco corrige problemas como: clareza de idéias, sintaxe, coesão, coerência textual e semântica, uma vez que essas questões irão depender da competência do revisor.

A finalidade deste artigo é mostrar a complexidade em desenvolver um corretor automático eletrônico já que o processamento da língua natural humana está ainda envolto em várias teorias que buscam o seu entendimento. Daí se vê a dificuldade em se criar uma ferramenta de revisão textual que atenda satisfatoriamente o seu objetivo. Isso não quer dizer que ele não seja útil, principalmente para as correções de erros de digitação (ortografia) e acentuação gráfica, apesar de que, muitas vezes, não consegue identificar determinada palavra por não constar no seu banco de dados.

Apesar do grande avanço da Informática, da Lingüística, e de áreas afins como Biologia, Psicologia, Filosofia, por que é tão difícil desenvolver um programa de revisor de texto no computador?

O problema é que, para se desenvolver esse programa, deparamos com uma área muito complexa, que é o estudo da língua. Não é simples entender seu conceito, funcionamento e sua estrutura, muito pelo contrário. Por isso, há séculos estuda-se acirradamente tudo o que a envolve, desde sua aquisição até a maneira como ela é usada.

Mas, ao se falar a respeito de corretor ou revisor, temos que ter em mente o conceito de texto, pois esse é o elemento de trabalho do corretor. Esse conceito dependerá das concepções que se tenha de língua e de sujeito. Neste ponto, diz Ingedore G. Villaça Koch (2003: 16):

$\mathrm{Na}$ concepção de língua como código - portanto, como mero instrumento de comunicação - e de sujeito como (pre)determinado pelo sistema, o texto é visto como simples produto da codificação de um emissor a ser decodificado pelo leitor/ouvinte, bastando a este, para tanto, o conhecimento do código, já que o texto, uma vez codificado, é totalmente explícito. Também nesta concepção o papel do "decodificador" é essencialmente passivo. Já na concepção interacional (dialógica) da língua, na qual os sujeitos são vistos como atores/construtores sociais, o texto passa a ser considerado o próprio lugar da interação e os interlocutores, como sujeitos ativos que - dialogicamente - nele se constroem e são construídos. Desta forma há lugar, no texto, para toda uma gama de implícitos, dos mais variados tipos, 


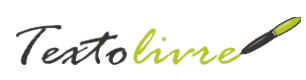

somente detectáveis quando se tem, como pano de fundo, o contexto sociocognitivo dos participantes da interação.

Podemos dizer, então, que sendo o texto o lugar de interação, a construção de sentidos acontece pela cognição social dos participantes e, portanto, o corretor eletrônico por não ser capaz dessa troca dialógica, torna-se falho em suas correções.

Ao pensarmos no significado das línguas nos deparamos com uma área da lingüística que diz respeito à semântica, e temos como exemplo o que diz o Professor José Luiz Fiorin, em seu livro Introdução à Lingüística II (2005:137) :

A definição de semântica como a área da lingüística que estuda o significado das línguas naturais é bastante consensual. Essa definição é, no entanto, pouco esclarecedora, porque, para entendê-la, precisamos definir, antes, o que é significado. E essa é uma tarefa árdua! Especialmente porque os semanticistas têm diferentes visões a respeito do que seja o significado e a significação. E por isso que podemos dizer que há semântica de todo tipo. Há semântica textual, semântica cognitiva, semântica lexical. Há semântica argumentativa, semântica discursiva... Todas elas estudam o significado, cada uma do seu jeito. Tamanha variedade mostra que o estudo do significado pode ser feito de vários ângulos.

Diante das palavras de Fiorin, concluímos que para definir o significado de uma palavra ou de uma expressão não é uma tarefa fácil, mas que somente é possível por intermédio do homem e não por um banco de dados de um robô.

De acordo com Ferdinand de Saussure, o signo é uma relação entre um significante e um significado, e não entre uma palavra e uma coisa. Sendo assim, a interpretação compreende não só o significante isolado, mas todos os elementos internos e externos ao sistema lingüístico. Por isso, torna-se difícil criar um corretor gramatical que garanta uma abrangência de questões sintáxica, semântica e pragmática para a eficácia de uma revisão. Podemos perceber isso no exemplo citado por Márcia Cançado (2005:13):

(...) o conhecimento semântico que o falante do português do Brasil tem o leva a atribuir duas interpretações para a sentença abaixo:

(3) A gatinha da minha vizinha anda doente.

Pelo conhecimento semântico do falante, a frase (3) torna-se a ambígua, pois "gatinha" tanto pode ser um felino como uma metáfora para mulher. E essa distinção será detectada pelo leitor/ouvinte por meio do contexto, o que não seria possível ao corretor eletrônico. Diante dessa questão, fica claro que a correção de um texto não é simplista, não se faz pela decodificação de palavras, porque o texto não é feito de códigos rígidos - conjunto de palavras com seus respectivos conceitos - nem tudo o que está explícito, em palavras, no texto, estará explícito com relação ao seu sentido no texto. O significado vai depender do contexto em que foi usado.

É necessário, portanto, que o profissional que revisa seja um bom leitor, para que haja uma interação eficaz. Ler um texto é dialogar com o autor, e assim, conseguir fazer inferências, compreender as metáforas existentes, encontrar os implícitos e, conseqüentemente, detectar problemas que estejam prejudicando a compreensão textual como coerência, coesão, pontuação, acentuação gráfica, ortografia. Esse é mais um dos problemas do corretor eletrônico, ele não lê o texto, apenas compara o que é digitado com o que está armazenado em seu banco de dados. Por isso, acontecem erros, como no exemplo citado abaixo, feita pelo corretor do Office do Word: 
(1) "Essa oração e encinada por Jezus".

O corretor detectou dois erros ortográficos, o da palavra "encinada" e "Jezus", baseado em semelhanças, sugeriu para aquela: empenada, empinada, encanada, encenada, encenadas, mas não sugeriu ensinada que é a palavra adequada para o contexto da frase. Para Jezus, sugeriu: gebos, geios, gelos, gesso, gessos, mas não sugeriu Jesus, porque esse nome próprio não consta de seu banco. Além disso, não acentuou o verbo, pois não conseguiu distinguir o presente do indicativo do verbo ser da conjunção $e$. Por esse simples exemplo, podemos ver que a revisão não é um mero reconhecimento de palavras. A revisão depende da relação entre as palavras e sua inserção no contexto para a compreensão de seu sentido.

Outro exemplo pertinente ao que temos falado é o caso da seguinte frase:

(2) "O vidro da janela é de ferro".

O corretor considerou correta a sentença. Realmente, considerando a frase do ponto de vista morfológico, sintático e estrutural, ela está correta, mas, semanticamente é incoerente, pois vidro não é ferro. Mais uma vez, pode-se perceber a deficiência do corretor.

Para construir um corretor eficiente, precisa-se estudar toda a complexidade da linguagem que gira em torno dos conhecimentos morfológicos, sintáticos, semânticos, pragmáticos, semióticos, discursivos, psicolingüísticos, etc., pois a língua é um todo que se separa em partes com o propósito de análise, de didática e de pesquisa. Por isso é um estudo relevante e fundamental para se criar um programa que "copie" a língua do ser humano.

Diante disso, pode-se dizer que os programas de correção ainda são bastante falhos. Não se pode confiar plenamente em suas correções, visto que há falhas facilmente resolvidas por um profissional de revisão de texto. O programa não consegue analisar a estrutura do texto, que na maioria das vezes é bem complexa. O corretor eletrônico, por ser um robô, só faz o que nele está programado. Então, o problema está com o programador de sistemas? Não se pode dizer isso, pois o problema não se limita a questões técnicas de informática. O "cérebro" do computador só entende de códigos, símbolos, mas a linguagem é muito mais que símbolos e códigos, por isso revisar não é apenas decodificar, saber regras gramaticais, é ir além do que está visível, buscar o implícito. Como um "cérebro mecânico", que só sabe ler códigos, conseguirá ler e corrigir o que está implícito? Um exemplo interessante que circula na internet é este a seguir:

Naão ioponrta em qaul oedrm as ltreas de uma prlvaaa eãtso, a úcnia csioa iprotmatne é que a piremria e útmlia lrteas ejteasm no lagur ctreo. O rtseo pdoe ser uma ttaol bçganua que vcoê pdoe adnia ler sem plbormea. Itso é pquroe nós não lomes cdaa ltrea isladoa, mas a plravaa cmooo um tdoo.

Nesse exemplo o corretor não conseguiu identificar quase nenhuma dessas palavras. Ele até as considerou erradas, mas não sugeriu nenhuma outra ortografia, pois elas não constam em seu banco de dados. Ele não capta o contexto, simplesmente faz a decodificação da palavra. Nós, no entanto, com mínimo esforço, conseguimos inferir significados e entender o que está escrito. O corretor eletrônico é mecânico e não dinâmico; mas o Revisor, além do conhecimento das normas da NGB, possui intuição lingüística.

O funcionamento da mente humana é maravilhoso e perfeito, somos capazes de falar e escrever de diversas maneiras. Se necessário, usamos novos códigos lingüísticos, em diferentes situações, e a mente do outro (leitor/ouvinte) é capaz de captar a mensagem. Um código da internet que surgiu com o chat, msn é o "internetês": 
Po.kra.eh.q.taum.falandu.q.o.proc.naum.funfa” esplicassaums:

"o.kra.dis.q.funfava,dis.ae.oq.tu.axa.

Ew.to.axandu.q.essa.promossaum.eh.mo.skema,

ma.naum.vaum.fase.issu.cmg.naum.falows

(Pô cara, é que estão falando que o processador não funciona", o cara disse que funcionava. Diz aí o que você acha? Eu estou achando que essa promoção é o maior esquema, mas não vão fazer isso comigo não). ${ }^{1}$

Esse exemplo foi tirado do fórum da campanha "Eu sei escrever!" na qual se questionava a possibilidade de inserir corretores automáticos nas conversas do chat, e-mail, msn, etc. Hoje, já os encontramos em navegadores e e-mails. O objetivo dessa campanha era ter um padrão lingüístico, para que qualquer pessoa pudesse entender o que os outros diziam e para que elas não acostumas sem a escrever "errado". Mas houve e há muitas opiniões diversas a respeito do propósito dessa campanha. José Luiz Fiorin em seu artigo encontrado no endereço $<\underline{\text { http: } / / w w w . l e t r a s . u f m g . b r} / \mathrm{ar}-$ quivos/matte/ievidosol/Fiorin.pdf $>$, argumenta a respeito do questionamento "A internet vai acabar com a língua portuguesa?". Nele encontram-se muitos argumentos que reforçam a inutilidade de um corretor eletrônico nas conversas do chat, msn, e-mail. A questão é que somos capazes de diferenciar as diversas situações - gêneros - e suas respectivas linguagens. Há gêneros que não exigem nenhuma formalidade, ao contrário, requerem informalidade. O corretor automático foi criado com base nas normas da NGB para atender a trabalhos que exigiam essa formalidade e não especificamente aos gêneros chat, msn e e-mail que utilizam uma linguagem informal. As pessoas não podem impor que todo tipo de situação lingüística seja amparado à norma-padrão. Elas precisam aprender a lidar com essa diversidade de gêneros e saber usá-las nos seus respectivos contextos. A importância da revisão é inquestionável nos contextos formais, porém - por mais avançada que seja a tecnologia - o corretor automático dificilmente conseguirá imitar a mente, a inteligência e o bom senso humano. Visto que a revisão não é um processo mecânico, e sim, dinâmico.

Apesar de todas essas dificuldades para se criar um corretor mais eficaz, pode-se aprimorar os já existentes no mercado que têm como objetivo a correção ortográfica e gramatical. A exemplo de um bom corretor, lembrado pela Professora Ana Cristina Fricke Matte, no chat do evento $1^{\circ}$ Evidosol, podemos citar o do OpenOffice:

O corretor gramatical do OpenOffice para mim eh o melhor: ele nao so diz que pode estar errado como mostra a regra que estaria sendo violada. Assim a pessoa acaba aprendendo as regras e se torna mais independente. No entanto, se o corretor nao marcar que a ortografia esta errada, o aluno jamais tera qualquer desconfianca a esse respeito.

(http://evidosol1.0.textolivre.org/RegistrosDasPalestras/mesaRedonda.html - [16:41:00] <acris>)

A estratégia citada é interessante, pois o usuário tem a oportunidade de decidir se realmente violou ou não, e, com isso, fixa e aprende melhor a norma-padrão, tornando-se mais independente. Esse tipo de corretor é muito útil até mesmo em línguas estrangeiras, pois é mais uma maneira de se aprender as normas de outra língua.

No debate ocorrido, nesse mesmo evento, com o Professor José Luiz Fiorin, entrou em questionamento se o verificador ortográfico e gramatical "desensinavam" os alunos a escrever. No caso de o corretor corrigir automaticamente - sem destacar o erro e nem mostrar a regra violada - pode sim ser um problema, mas, como disse o Professor Fiorin (chat da mesa-redonda do $1^{\circ}$ Evidosol):

1 C'FÓRUMPCS. Disponível em:

$<$ http://www.forumpcs.com.br/coluna.php?b=117373 $>$. Acesso em 10 dez. 2007. 
A questão é que a nossa escola tem que lidar com problemas de corretores, etc. Assim como o ensino de matemática tem que lidar com calculadoras. Não podemos parar o mundo. A escola é que tem que se adaptar. Afinal, já diziam os latinos: non scholae, sed vitae discimus. (http://evidosol1.0.textolivre.org/RegistrosDasPalestras/mesaRedonda.html - [16:40:58] <Fiorin>)

O corretor pode ser um instrumento para o aprendizado da língua padrão se, ao corrigir, especificar a regra aparentemente violada. Mas, além de todos os problemas citados, encontram-se também, em seu banco de dados, erros ortográficos. Além disso, existem alguns corretores que corrigem automaticamente, sem indicar - através de traços vermelhos ou verdes - a palavra incorretamente grafada, e assim, a pessoa não terá ciência de sua falha e continuará cometendo o mesmo erro em textos que exijam a norma-padrão.

É importante deixar claro que o corretor automático não tem a função de substituir o revisor profissional, ele serve apenas como auxiliar de revisão. E mesmo em sua função de auxiliar, esse artigo nos mostra o quanto o corretor automático é falho. Agora, se há alguém que tenha o objetivo de, no futuro, criar um software tão eficaz quanto a mente humana, que possa, portanto, substituir o ser humano, podemos dizer que este terá um árduo trabalho. E, mesmo assim, terá seu objetivo frustrado, pois diante de todas essas complexidades citadas é improvável que se crie um software que seja capaz de substituir o ser humano.

\section{Referências Bibliográficas}

C'FÓRUMPCS. Disponível em: <http://www.forumpcs.com.br/coluna.php?b=117373>. $<$ http://www.bestlinux.com.br/index.php?option=com content\&task=view\&id=79\&Itemid=162 $>$. Acesso em 10 dez. 2007. CANÇADO, Márcia. Manual de Semântica, noções básicas e exercícios. Belo Horizonte: UFMG, 2005.

FIORIN, José Luiz. Introdução à Lingüistica II. Princípios de análise. São Paulo: Contexto, 2005. KOCH, I.G.V. Desvendando os segredos do texto. 2.ed. São Paulo: Cortez, 2003.

SAUSSURE, Ferdinand de. Curso de lingüística geral. 19.ed. São Paulo: Cultrix, 1994.

$<$ http://evidosol1.0.textolivre.org/RegistrosDasPalestras/mesaRedonda.html $>$

$<$ http://www.letras.ufmg.br/arquivos/matte/ievidosol/Fiorin.pdf $>$ 